\title{
Hypocalcemia in the critically ill: a mini-review
}

\begin{abstract}
In this mini-review of hypocalcemia in the critically ill patient historical and new insights in the function of the PTH-vitamin D axis are discussed Special attention is given to the role of locally tissue produced calcitriol in the immune system and in the inflammatory cytokine response of the vitamin D deficiënt critically ill patient.Future directions in this research area and in the forthcoming research on the use of the anabolic recombinant PTH analogues in critical care medicine are discussed.
\end{abstract}

Keywords: hypocalcemia, PTH-vitamin D, PTH, 25(OH)D3, 1.25 di-(OH)D3.

\author{
Volume 5 Issue 4 - 2017
}

\author{
Michael AB Naafs \\ Dutch Internist Endocrinologist, Naafs International Health \\ Consultancy, Netherlands \\ Correspondence: Michael AB Naafs, Dutch Internist \\ Endocrinologist, Health Consultant at Naafs International \\ Health Consultancy, Rhodoslaan 20,7577KN, Oldenzaal, The \\ Netherlands, Tel +3I68I589079, Email naafsmichael@gmail.com
}

Received: August 30, 2017| Published: September 27, 2017

Abbreviations: PTH, parathyroid hormone; cAMP, cyclic adenosine 3,5, monophosphate; ECF, extracellular fluid compartiment; VDRs, vitamin D receptors; AMP, antimicrobial peptide; BMD, bone mineral density; CRP, $\mathrm{C}$ - reactive protein.

\section{Introduction}

In a balanced diet, roughly $1000 \mathrm{mg}$ of calcium is ingested each day and about $200 \mathrm{mg}$ is secreted in the bile and other gastrointestinal secretions. Depending on the comcentrations of circulating parathyroid hormone (PTH) and active i.25.di-(OH)D3 about $200-400 \mathrm{mg}$ is absorbed from the intestine each day. The remaining calcium is excreted in the stool. Maintenance of body calcium stores depends on dietary calcium intake, absorption of the gastrintestinal tract and renal calcium excretion. PTH enhances distal tubular calcium reabsorption, independently of sodium, while proximal tubule calcium excretion is sodium dependent and coupled to phosphaturia,urinary cAMP (Cyclic Adenosine 3, 5, Monophosphate) and nephrogenous cAMP excretion.

About $99 \%$ of body calcium is stored in bone mainly as hydroxyapatite crystals.About $1 \%$ of calcium is freely exchangable with the extracellular fluid compartiment (ECF) and therefore is available to buffering changes in calcium balance. Normal total serum calcium concentrations range from 8,8 to $10,4 \mathrm{mg} / \mathrm{dl}$ or $2,20-2,60 \mathrm{mmol} / \mathrm{l}$. About $40 \%$ of the total blood calcium is bound to plasma proteins, primarily albumin. The remaining $60 \%$ includes ionized calcium and calcium complexed with phosphate and citrate. Ionized calcium is the physiologically active form and acts as an intracellular second messenger involved in skeletal muscle contraction, excitation-contraction coupling in cardiac and smooth muscle and activation of protein kinases and phosphorylation leading to the formation of other second messengers as cAMP and inositol 1,4,5triphosphate mediating the cellular response to numerous hormones including epinephrine, glucagon, secretin and cholecystokinin.

Ionized calcium is assumed to be $50 \%$ of the total serum calcium and can be estimated based on total serum calcium levels and albumin levels. In hypoalbuminemia measured total serum calcium is often low reflecting a low concentration of protein-bound calcium while ionized calcium may be normal. Measured total serum calcium decreases or increases by about $0,8 \mathrm{mg} / \mathrm{dl}$ or $0,2 \mathrm{mmol} / 1$ for every $\mathrm{g} /$ $\mathrm{dl}$ decrease or increase in albumin. Thus an albumin concentration of 2,0g/dl(normal 4,0g/dl) should itself reduce measured serum calcium by $1,6 \mathrm{mg} / \mathrm{dl}$ or $0,4 \mathrm{mmol} / 1$, Even in the presence of a normal serum albumin changes in blood $\mathrm{pH}$ can alter the equilibrium constant of the albumin-calcium complex with acidosis reducing the binding and alkalosis enhancing it. In critically ill or post-surgical patients with hypoalbuminemia correcting total serum calcium for albumin is not necessarily accurate because of changes in $\mathrm{pH}$ and affinity of calcium binding. ${ }^{1}$ A total serum calcium level less than 2,1 mmol/1 and an ionized calcium level of less than $1,0 \mathrm{mmol} / 1$ is defined as hypocalcaemia. ${ }^{2}$ Ionized calcium measurements offer additional benefits in the diagnosis of primary hyperparathyroidism because it is correlated with PTH levels and adenoma size and may be a more sensitive marker of disease severity than total serum calcium, which is an appropriate first-line biochemical test. ${ }^{3}$

Analysis for the ionized calcium level must be performed rapidly with whole blood to avoid changes in $\mathrm{pH}$ and anion chelation. Blood should be drawn in a heparinized syringe or an EDTA blood bottle which is transported to the gas analyzer in ice immediately for the best results. Falsely elevated ionized cacium levels may be seen with elevated acetaminophen levels, alcohol, hydralazine and hemolysis althogh this effect is modest. Falsely depressed levels can be seen with heparin, oxalate or hyperbilirubinemia. ${ }^{1-6}$

In cases of hypocalcemia serum magnesium should always be checked. Occasionally inadequate dietary magnesium as in malnutrition and chronic alcoholism can lead to hypomagnesemia. Excessive use of thiazide diuretics and long term proton pump inhibitor use are other causes of hypomagnesemia. Hypomagnesemia impairs parathormone (PTH) secretion resulting in hypocalcemia and hypophosphatemia. $^{7-9}$

The differentiall diagnosis ranges from (pseudo) hypoparathyroidism,renal failure.post-thyroidectomy surgery,acute pancreatitis to widespread osteoblastic metastasis in prostate and breast cancer. ${ }^{11,12}$ This mini-review will focus on hypocalcemia in the critically ill patient.

\section{Hypocalcemia in the critically ill}

The first clinical observations and studies in hypocalcemic critically ill patients date back to the early 70's and 80 's of the last century. ${ }^{1}$ The incidence of hypocalcemia in critically ill patients varies widely depending on the different underlying diseases and comorbidity. In an analysis of 12 studies performed between 1988 
and 2014 Aberegg believes the incidence of hypocalcemia in critically ill patients ranges from $50-88 \%{ }^{13}$

However some critical annotations must be made. Some studies used corrected calcium values while others measured ionized calcium. It is also not clear if the calcium measurements were made for diagnostic, screening, homeostatic or daily routine purposes. The only thing that is evident at present is that some $50 \%$ of critically ill patients in an ICU will have hypocalcemia at some moment at some day during their stay. ${ }^{13}$

Does that mean half of critically ill ICU patients has some latent disorder of calcium metabolism? Probably not but it is understandable that early studies focused on possible alterations in the PTH-Vitamin $\mathrm{D}$ axis in the hypocalcemic critically ill.

\section{The PTH-Vitamin D axis}

Zalago reviewd in 1992 earlier human and animal investigations and in vivo and in vitro studies. He concluded that hypocalcemia in critically ill patients usually results from impaired PTH secretion or action (end-organ resistance), impaired vitamin D synthesis or action or calcium chelation and precipitation. ${ }^{14}$

In a small 1999 study Lepage et al. ${ }^{15}$ showed significant decreases in ionized calcium during abdominal surgery with compensatory significant rises in PTH levels depending on the severity of the surgery. Hypomagnesemia was absent in this study thus PTH secretion seemed intact under these circumstances. Alterations in blood PH during anaesthesia were not present and there was also no relationship between the decrease in ionized calcium and blood transfusions.

In 2000 Lind et al. ${ }^{16}$ studied the dynamics of PTH secretion by a calcium chloride infusion on day 1 and 3 in 13 septic ICU patients with hypocalcemia and 13 surgical patients with normocalcemia. Serum PTH levels were increased in both groups. In both study groups an increased PTH secretion was found.

Is there end-organ resistance to PTH in hypocalcemic critically ill patients as Zalago suggested? End-organ resistance is tested in pseudohypoparathyroidism and in other disease states by PTH infusion followed by measuring the renal response in terms of phosphaturia and nephrogenous cAMP excretion. ${ }^{17}$ These studies were not done in hypocalcemic critically ill patients with normal serum magnesium levels.

In hypomagnesemic, hypocalcemic critically ill patients Rude et al showed already in 1976 that functional hypoparathyroidism and end -organ resistance to PTH was caused by magnesium deficiency only by administering PTH extract in these patients. The renal response was evaluated by measuring urinary cAMP excretion. Within minutes of i.v. magnesium administration serum PTH levels rose from undetectable levels to sky high. Restoring of the PTH end-organ resistance took at least 4 days. ${ }^{18}$

So the suggestions of Zalago for the existence of impaired PTH secretion and PTH end-organ resistance in hypocalcemic critically ill patients with normal serum magnesium levels can not be confirmed by evidence. Nevertheless these suggestions are widely cited in nearly all articles about this subject.

\section{Vitamin D and metabolites}

Vitamin D deficiency is common in ICU patients and prevalence rates range from $38 \%-100 \%$ in observational studies. ${ }^{19}$ Critically ill patients with a prolonged stay at an ICU may develop vitamin D deficiency for a number of reasons, including the lack of sunlight, malnutrition, decreased renal 1-alpha-hydroxylation in acute renal failure and increased tissue conversion of 25(OH)D3 to $1.25 \mathrm{di}-(\mathrm{OH})$ D3 during acute stress and inflammatory response..$^{20,21}$

Vitamin D is usually supplemented in critical care along with nutritional support. Approximately 100-300 IU of vitamin D2 or vitamin D3 daily is provided in standard and enteral parenteral regimen. ${ }^{22}$ It is questionable whether this relatively small amount is sufficient.

Vitamin D deficiency could contribute certainly to hypocalcemia in the critically ill by diminishing gastro-intestinal absorption of calcium and decreasing renal tubular reabsorption of calcium.

Lee has postulated the theoretical concept of functional vitamin D deficiency in critical illness. ${ }^{19,21}$ This means that the clinical consequences of vitamin D deficiency are not only dependent on the severity of vitamin $\mathrm{D}$ depletion but are also related to tissue requirements. In such a model the ciculating $25(\mathrm{OH})$ D3 pool represents a substrate reservoir for conversion to active metabolites at the tissue level during acute stress.

It is conceivable that the physiological needs of appropriate conversion of the inactive $25(\mathrm{OH}) \mathrm{D} 3$ to the biologically active prohormone $1.25 \mathrm{di}-(\mathrm{OH}) \mathrm{D} 3$ is generated through a regulatory system of local and renal 1-alpha hydroxylases to satisfy the demand of tissue requirements. When ciculating vitamin D levels are sufficient and tissue requirement is relatively low organ function is normal and physical health maintained.

In acute stress and critical illness however,multifactorial hypocalcemia is very common and may lead to a compensatory rise in PTH levels which would enhance the conversion of 25(OH)D3 to 1.25 di-(OH)D3 to maintain calcium homeostasis as a result of increased bone resorption and intestinal calcium absorption,respectively. Due to secondary hyperparathyroidism the consumption of $25(\mathrm{OH}) \mathrm{D} 3$ would further exacerbate vitamin D deficiency. This could be also an explanation for the high prevalence of vitamin D deficiency in the ICU.

Evidence in support of this hypothesis came from studies that showed secondary hyperparathyroidism was linked to hypocalcemia and low 25(OH)D3 levels. ${ }^{23-25}$

Furthermore in contrast to the general population in which calcitriol levels are maintained within the normal range despite low $25(\mathrm{OH}) \mathrm{D} 3$ levels calcitriol levels are up to $50 \%$ lower in ICU patients. Calcitriol levels correlated positively with $25(\mathrm{OH}) \mathrm{D} 3$ in this setting. This suggests substrate deficiency may be more profound in critically ill patients. ${ }^{20,25-28}$ Therefore vitamin D deficiency in the ICU is a mismatch between substrate supply and tissue requirements. Despite stimulation of renal 1-alpha hydroxylase local mitochondrial tissue 1-a hydroxylases are unable to generate adequate 1.25 di- $(\mathrm{OH}) \mathrm{D} 3$ levels. PTH resistance associated with hypomagnesemia, acute renal failure and functional hypoparathyroidim may further compromise 1.25 di- $(\mathrm{OH}) \mathrm{D} 3$ production.

It is clear that in this vision the widely held concept of vitamin D end-organ resistance in the absence of hypomagnesemia, as suggested by Zalago in 1992, has been abandonned completely.

In a 2014 systematic review and meta-analysis de Haan et al 
showed Vitamin D deficiency to be a risk factor for infection, sepsis and mortality in the critically ill. ${ }^{29}$

\section{The cytokines}

Proinflammatory cytokines such as interleukin-1(IL-1), interleukin-6 (Il-6) and tumor necrosis factor -alpha (TNF-alpha) are important mediators of the acute response to critical illness. An interplay between serum calcium, the PTH-vitamin D axis and the cellular immune system has been proposed.$^{30}$ Calcitriol has a central role in this interplay by its paracrine and autocrine non-skeletal effects.

Nearly $35 y e a r s$ ago the presence of vitamin D receptors (VDRs) in activated human immune cells was discovered as well as the ability of 1.25 di- $(\mathrm{OH}) \mathrm{D} 3$ to inhibit $\mathrm{T}$ cell proliferation and the ability of activated macrophages to produce $1.25 \mathrm{di}-(\mathrm{OH}) \mathrm{D} 3$ in patients with sarcoidosis. ${ }^{31-33}$ This conversion has not been found in the tuberculosis granuloma and is specific for the sarcoid granuloma for unknown reasons.Nevertheless patients with a vitamin D deficiency are more susceptible to TB and recover faster with vitamin D supplementation to their tuberculostatic regimen. ${ }^{34}$ It now appears that 1.25.di- $(\mathrm{OH})$ D3 modulates the immune response in macrophages by upregulating the expression of the antimicrobial peptides cathelicidin and defensin which inhibit the intracellular growth of M.tuberculosis. Apart from the antimicrobial effects $1.25 \mathrm{di}(\mathrm{OH}) \mathrm{D} 3$ also modulates the antigen presentation and secretion of chemokines and cytokines enhancing macrophage innate immune function by a cooperating system of tolllike receptors and vitamin D receptors as described below. ${ }^{34-36}$

The significance of these observations concerning innate immunity was clarified with the discovery of toll-like receptors ( TLRs) in monocytes and macrophages nearly 25years later. TLRs are transmembrane receptors and recognize microbial ligands including bacterial lipopolysaccharides and are responsible for the transcriptional induction of genes like CYP27B1 and the vitamin D receptor (VDR). ${ }^{37}$

In this way circulating serum $25(\mathrm{OH}) \mathrm{D} 3$ enters monocytes, is converted by mitochondrial 1-alpha hydroxylase to active $1.25 \mathrm{di}-$ $(\mathrm{OH}) \mathrm{D} 3$ and then binds to the VDR. The complex of $1.25 \mathrm{di}-(\mathrm{OH}) \mathrm{D} 3$ VDR bound leads to the transcription of cathelicidin expression, which is a potent antimicrobial peptide (AMP) that promotes autophagy. ${ }^{38}$ Cathelicidin expression can be activated by 1.25 di- $(\mathrm{OH}) \mathrm{D} 3$ alone. Another important AMP, defensin, is also produced by TLR induced expression. ${ }^{35,38-40}$ These AMPs are now in phase 1 and phase 2 clinical trial stage..$^{35}$

Markers of systemic inflammation including C-reactive protein (CRP), TNF-alpha and interleukin-6 (IL-6) are typically increased during ICU stay. Prolonged hypercytokinemia leads to multi-organ failure. $^{20}$

Van den Berghe et al. ${ }^{20}$ showed that these circulating levels of inflammation biomarkers were 5-400 fold higher upon intensive care admission. In prolonged critically ill patients parenteral vitamin D3 supplementation of 500 IU per day reduced CRP and IL-6 levels by approximately $40 \%$ and $60 \%$ respectively and the fall of the inflammatory markers was significant compared to the control group receiving 200 IU vitamin D3 daily. ${ }^{20,21}$

The multiple functions of vitamin D in the immune system's response to infection lead to the suggestion that vitamin $\mathrm{D}$ could be useful in the treatment of sepsis. Gram-negative sepsis in particular is known to be associated with hypocalcemia and vitamin D deficiency in the critically ill. The VDR recognizes the lipopolysaccharides in theGram-negative bacterial outer membrane. ${ }^{41}$

Jeng et al. ${ }^{37}$ showed that vitamin D binding protein levels are signicantly lower in critically ill subjects with sepsis compared to critically ill patients without sepsis and healthy controls. When they examined plasma levels of the endogenous AMP LL-37 (cathelicidin) they found that lower levels of LL-37 were associated with lower levels of $25(\mathrm{OH}) \mathrm{D} 3$. This association supports in vivo data that vitamin $\mathrm{D}$ plays some roles in regulating the production of AMPs such as LL-37 in cultured macrophages.

Since many cells of the immune system have VDRs vitamin D status may prove to be an important factor in the management of the sepsis syndrome and critical illness. In this promising research area a lot has to be elucidated yet.

Recently De Fillipis et al. ${ }^{42}$ showed that vitamin D reduces the inflammatory response in a gingivitis model by modulating the human AMP beta-defensin- $3 .{ }^{42}$

Results in healthy volunteers exposed to experimental human endotoxinemia didn't show an association between vitamin D and cytokine levels. ${ }^{43}$ May be that decreased vitamin D binding protein levels which are normal in healthy volunteers play a crucial yet unknown role in bacterial susceptibility. ${ }^{41}$

\section{Treatment}

\section{Correcting hypocalcemia}

The treatment of hypocalcemia depends on the cause, the severity, the presence of symptoms and the speed of developing hypocalcemia. ${ }^{2}$ Mostly hypocalcemia is mild and requires only supportive therapy. Sometimes it is severe with seizures, tetany, refractory hypotension and cardiac arrythmias that require an aggressive approach.

Studies in critically ill patients have yielded conflicting results regarding calcium supplementation. Some studies suggest that serum calcium normalizes mostly within 4days after admission to the ICU and that low levels of calcium are protective and attempted correction may be harmful. ${ }^{1}$ In contrast other studies have concluded thath both mild and moderate hypocalcemia are associated with increased mortality. One large retrospective study showed that callcium supplementation improved 28 day survival in the ICU in critically ill patients. ${ }^{45,46}$

In the MIMIC -2 study the only large retrospective study of sufficient statitiscal power to date both hypercalcemia and hypocalcemia were associated with altered mortality in a complex form. Interestingly mild hypercalcemia on ICU admission was found to be protective and was associated with reduction in 28-day mortality while hypocalcemia showed the opposit effect. This curve showed an U-shape, implicating endless calcium supplementation may be harmful. However many confounders were present as e.g the lack of standardized calcium supplementation, hypovitaminosis D3, absence of dialysis patients and differences in timing of blood samples. A sub analysis showed later also a benificial effect of calcium supplementation on 90-day mortality. Follow up data studying morbidity and the overall clinical outcome are not available because too many patients were lost in the follow-up. ${ }^{46}$ 
Are there evidence based guidelines for correcting hypocalcemia? No,the Endocrine Society released in september 2016 an Emergency Guidance for the management of acute hypocalcemia that is so very brief it has no additional value for daily clinical practice. ${ }^{47}$

\section{A useful scheme would be}

Mild: (Ionized Calcium; 1, 0-1,2mmol/1: Calciumgluconate i.v.; 1-2g over 2hours.

Severe: Without seizure or tetany; $0,5 \mathrm{mg} / \mathrm{kg} / \mathrm{hr}$ i.v; may be increased to $2 \mathrm{mg} / \mathrm{kg} / \mathrm{hr}$ not to exceed $3-4 \mathrm{~g}$ i.v over 4 hours.

Hypocalcemic tetany: $3 \mathrm{~g}$ calciumgluconate i.v over 5-10minutes, followed by continous i.v infusion of $0.5 \mathrm{mg} / \mathrm{kg} / \mathrm{hr}$ that may be increased to $2 \mathrm{mg} / \mathrm{kg} / \mathrm{hr}$. Monitor serum calcium q4-6hours to maintain serum calcium levels.

\section{Vitamin D supplementation}

In general there are two U.S guidelines issued for vitamin D supplementation in the general population at risk for vitamin D defieciency. These are released by the IOM (Institute of Medicine) and by a Task Force of the Endocrine Society. They differ in their definitions of vitamin deficiency by using different cut-offs of $25(\mathrm{OH})$ D3 levels. To complicate matters further the Endocrine Society Task Force focuses on diseased people and advises higher supplemental doses while the IOM focuses on the normal population. ${ }^{48}$ U.K NICE guidelines are directed at population groups at risk but do not refer in their recommendations to the ICU group of patients. An initial i.v dose of 50.000-60.000 IU should be considered. In fact it is not known if vitamin D should be given as loading i.v bolus, weekly i.v doses or only by daily TPN or feeding tube when oral supplementation is not possible..$^{22,49,50}$

In studies of vitamin D supplementation in critically ill patients different vitamin D formulas were used. The Spanish Mata-Granados Group demonstrated that 60.000 IU cholecalciferol administered orally at day 0 and day 4 evoked a significant rise in 25(OH)D3 and 1.25. di- $(\mathrm{OH}) \mathrm{D} 3$ levels whereas the application of $2 \mathrm{ug}$ calcitriol intravenously on alternate days had no impact on these levels in septic patients. $^{28}$

In another small study 540.000 IU cholecalciferol or placebo was delivered once by feedtube or orally to 25 critically ill patients at an intensive care unit Already on day 1 the 25(OH)D3 levels were significantly higher in the intervention group. On day 1 the 1.25 di- $(\mathrm{OH}) \mathrm{D} 3$ levels were significantly higher but this was only very transiently. Eighty percent of the vitamin D treated patients achieved 25(OH)D3 levels above 30ng/ml.

Of interest is the transient and short-lived rise of $1.25 \mathrm{di}-(\mathrm{OH})$ D3 levels. Probably this was due to a substrate boost for local tissue mitochondrial 1-alpha-hydroxylase activity. There were large individual differences in 25(OH)D3 levels probably due to large variations in gastrointestinal absorption. ${ }^{51}$ Intravenous formulations could overcome this problem but i.v administration of calcitriol had no impact on 25(OH)D3 and $1.25 \mathrm{di}-(\mathrm{OH}) \mathrm{D} 3$ levels in septic patients as shown in the Mata-Granados study. ${ }^{28}$

It seems that the local tissue conversion of $25(\mathrm{OH}) \mathrm{D} 3$ to locally produced 1.25 di- $(\mathrm{OH})$ D3 is essential in vitamin D function as e.g stimulation of AMPS. ${ }^{37,38,41}$ This supports Lee's hypothesis that Vitamin D deficiency in the critically ill is a mismatch between substrate supply $(25(\mathrm{OH}) \mathrm{D} 3$, cholecalciferol) and tissue requirements further. ${ }^{19}$ So a "one fits it all" vitamin D supplementation regimen can't be given.

\section{Parathormone}

Human recombinant 1-84, full length, PTH (Natpara) proved to be efficacious and safe in the REPLACE study for the treatment of hypoparathyroidism. In the RACE study long-term treatment of hypoparathyroidism improved hypercalciuria as the 3-year analysis showed..$^{53}$ Another recombinant PTH analogue is the 1-34 teriparatide (Forteo) which showed to be superior to alendronate for increasing lumbar spine bone mineral density (BMD) in postmenopausal osteoporosis at 12 months of treatment. However teriparitide was not superior to alendronate in reducing fracture risk. ${ }^{54}$ Both these analogues have anabolic properties and effects. ${ }^{52-57}$ Studies about their efficacy in the hypocalcemia of the critically ill patient are awaiting as they could reverse or improve bone hyperresorption in the critically ill patient. ${ }^{27}$

\section{Conclusion}

Hypocalcemia occurs in about $50 \%$ of critically ill patients in an intensive care setting. Hypocalcemia should be measured by ionized calcium with a concomittant serum magnesium measurement. In cases of hypocacemia and hypomagnesemia the seum magnesium deficiency should be corrected always at first. When serum magnesium is normal there is no impaired PTH secretion or PTH end-organ resistance in the hypocalcemic critically ill patient neither there is a vitamin D end-organ resistance in the vitamin D deficiënt critically ill. Local tissue conversion of cholecalciferol by 1-alpha mitochondrial tissue hydroxylase seems to play an essential role in the critically ill patient's immune system function as eg the production of antimicobial peptides (AMPs) and in the acute inflammatory cytokine response. These functions of locally tissue produced calcitriol can only be performed when the circulating pool of substrate of cholecalciferol is sufficient. In septic critically ill patients a mismatch between substrate supply and tissue requirements frequently occurs and contributes to the high prevalence of vitamin D deficiency in critically ill patients. Evidence based guidelines for calcium-and vitamin D supplementation in critically ill patients are hardly present.Future research in the immune and other possible functions of locally produced calcitriol in vitamin D deficiënt critically ill patients might resolve these knowledge gaps. The anabolic effects of the recombinant PTH analogues in the critically ill patient will be another forthcoming research topic in critical care medicine.

\section{Acknowledgments}

None.

\section{Conflicts of interest}

The authors declare that there are no conflicts of interest.

\section{Funding}

None.

\section{References}

1. Jafri L, Khan AH, Azeem S. Ionized Calcium Measurement in Serum and Plasma by Ion-Selective Electrodes: Comparison of Measured and Calculated Parameters. Indian J Clin Biochem. 2014;29(3):327-332.

2. Cooper MS, Gittoes NJ. Diagnosis and management of hypocalcaemia. BMJ. 2008;336(7656):1298-1302. 
3. Tee MC, Holmes DT, Wiseman SM. Ionized vsserum calcium in the diagnosis of primary hyperparathyroidism:which is superior? Am J Surg. 2013;205(5):591-596.

4. Jean G, Granjon S, Zaoui E, et al. Usefullness and feasibility of measuring ionized calcium in hemodialysis patients. Clin Kidney J. 2015;8(4):378-387.

5. Sava L, Pillai S, More U, et al. Serum calcium measurement: Total versus free (ionized) calcium. Indian J Clin Biochem. 2005;20(2):158-161.

6. Banfi G, Salvagno GL, Lippi G. The role of ethylenediamine tetraacetic acid (EDTA) as in vitro anticoagulant for diagnostic purposes. Clin Chem Lab Med. 2007;45(5):565-576.

7. Nagvi A. Two Patients with Parathyroid Hormone Suppression Caused by Proton Pump Inhibitors. Am J Hosp Med. 2017;1(3):2017-2023.

8. Sica DA. Diuretic-Related Side Effects: Development and Treatment. $J$ Clin Hypertens (Greenwich). 2004;6(9):532-540.

9. Elisaf M, Kalaitzidis R. Metabolic Abnormalities in Alcoholic Patients:Focus on Acid Base and Electrolyte Disorders. J Alcohol Drug Depend. 2015;3:185.

10. Mario Skugor. Hypocalcemia. Cleveland Clinic. 2014.

11. Chernow B, Zaloga G, McFadden E, et al. Hypocalcemia in critically ill patients. Crit Care Med. 1982;10(12):848-851.

12. Burchard KW, Gann DS, Colliton J, et al. Ionized calcium,parathormone and mortality in critically ill surgical patients. Ann Surg. 1990;212(4):543-550.

13. Aberegg SK. Ionized Calcium in the ICU: Should it be Measured and Corrected? Chest. 2016;149(3):846-855.

14. Zalago GP. Hypocalcemia in critically ill patients. Crit Care Med. 1992;20(2):251-262.

15. Lepage R, Legare G, Racicot C, et al. Hypocalcemia Induced during Major and Minor Abdominal Surgery in Humans. J Clin Endocrinol Metab. 1999;84(8):2654-2658.

16. Lind L, Carlstedt F, Rastad J, et al. Hypocalcemia and parathyroid hormone secretion in critically ill patients. Crit Care Med. 2000;28(1):93-99.

17. Naafs MA, Fischer HR, van der Velden PC, et al. End-organ resistance to PTH infusion in hypercalcaemic and normocalcaemic patients with solid tumours. Acta Endocrinol (Copenh). 1986;113(4):543-550.

18. Rude RK, Oldham SB, Singer FR. Functional hypoparathyroidism and parathyroid hormone end-organ resistance in human magnesium deficiency. Clin Endocrinol (Oxf). 1976;5(3):209-224.

19. Lee P. Vitamin D metabolism and deficiency in critical illness. Best Pract Res Clin Endocrinol Metab. 2011;25(5):769-781.

20. Van den Berghe G, Van Roosbroeck D, Van Hove P, et al. Bone turnover in prolonged critical illness:effect of vitamin D. J Clin Endocrinol Metab. 2003;88(10):4623-4632.

21. Lee P, Nair P, Eisman JA, et al. Vitamin D deficiency in the intensive care unit:an invisibleaccomplice to morbidity and mortality? Intensive Care Med. 2009;35(12):2028-2032.

22. Singer P, Berger M, Van den Berghe G, et al. ESPEN Guidelines on Parenteral Nutrition: intensive care. Clin Nutrit. 2009;18(4):387-400.

23. Lucidarme O, Messai E, Mazzoni T, et al. Incidence and risk factors of vitamin $\mathrm{D}$ deficiency in critically ill patients: results from a prospective observational study. Intensive Care Med. 2010;36(9):1609-1611.

24. Flynn L, Zimmerman LH, McNorton K, et al. Effects of vitamin D deficiency in criticall ill surgical patients. Am J Surg. 2012;203(3):379-382.

25. Van den Berghe G, Wouters P, Weekers F, et al. Reactivation of pituitary hormone release and metabolic improvement by infusion of growth hormone releasing peptide and thyrotropin-releasing hormone in patients with protracted critical illness. J Clin Endocrinol Metab. 1999;8(4):1311-1323.

26. Holick MF. Vitamin D deficiency. N Engl J Med. 2007;357(3):266-281.

27. Nierman DM, Mechanick JL. Bone hyperresorption is prevalent in chronically critically ill patients. Chest. 1998;114(4):1122-1128.

28. Mata-Granados JM, Vargas-Vasserot J, Ferreiro-Vera C, et al. Evaluation of the vitamin D system (VDES) status and response to treatment of patients in intensive care units (ICUs) using an on-line SPELC-MS/MS method. J Steroid Biochem Mol Biol. 2010;121(1-2):452-455.

29. de Haan K, Groeneveld JA, de Geus HR, et al. Vitamin D deficiency as a risk factor for infection,sepsis and mortality in the critically ill: systematic review and meta-analysis. Crit Care. 2014;18(6):660.

30. Hotchkiss RS, Karl IE. Calcium:a regulator of the inflammatory response in endotoxinemia and sepsis. New Horiz. 1996;4(1):58-71.

31. Provvedini DM, Tsoukas CD, Deftos LJ, et al. 1.25-dihydroxyvitamin D3 receptors in human. leukocytes. 1983;221(4616):1181-1183.

32. Rigby WF, Stacey T, Fanger MW. Inhibition of $\mathrm{T}$ lymphocyte mitogenesis by 1.25 dihydroxyvitamin D3 (calcitriol). J Clin Invest. 1984;74(4):1451-1455.

33. Adams JS, Sharma OP, Gacad MA, et al. Metabolism of 25-hydroxyvitamin D3 by cultured pumonary alveolar macrophages in sarcoidosis. $J$ Clin Invest. 1983;72(5):1856-1860.

34. Fecchini L, Venturini E, Galli L, et al. Vitamin D and tuberculosis:a review on a hot topic. J Chemother. 2015;27(3):128-138.

35. Naafs Michael AB. The Antimicrobial Peptides: Ready for Clinical Trials? Infection Control tips 2017 submitted for publication. 2015.

36. Paramasivam Selvaraj, Kolloli Afsal, Murugesan Harishankar. Vitamin D and macrophage functions in tuberculosis. Macrophage. 2015.

37. Liu PT, Stenger S, Li $\mathrm{H}$, et al. Toll-like receptor triggering of a vitamin D-mediated human antimicrobial response. Science. 2016;311(5768):1770-1773.

38. Yuk JM, Shin DM, Lee HM, et al. Vitamin D3 induces autophagy in human monocytes/macrophages via cathelicidin. Cell Host Microbe. 2009;6:231-243.

39. Hewison M. Antibacterial effects of vitamin D. Nat Rev Endocrinol. 2011;7(6):337-345.

40. Adams JS, Ren S, Liu PT, et al. Vitamin D-directed rheostatic regulation of monocyte antibacterial responses. J Immunol. 2009;182(7):4289-4295.

41. Jeng L, Yamshchikow AV, Judd SE, et al. Alterations in vitamin D status and antimicrobial peptide levels in patients in the intensive care unit with sepsis. J Transl Med. 2009;23:7-28.

42. De Fillipis A, Florentino M, Guida L, et al. Vitamin D reduces the inflammatory by Porphyromanas gingivulis infection by modulating human beta-defensin-3 in human gingival epithelium and peridontal ligament cells. Int Immunopharmacol. 2017;47:106-117.

43. Kox M, van den Berg MJ, van der H oeven JG, et al. Vit D status is not associated with inflammatory cytokine levels during experimental human endotoxinemia. Clin Exp Immunol. 2013;171:231-236.

44. Steele T, Kolamunnage-Dona R, Downey C, et al. Assessment and clinical course of hypocalcemia in critical illness. Crit Care. 2013;17(3):R106.

45. Zhang $\mathrm{Z}, \mathrm{Xu} \mathrm{X}, \mathrm{Ni} \mathrm{H}$, et al. Predictive value of ionized calcium in critically ill patients:an analysis of a large database MIMIC 2. PLoS One. 2014;9(4):e95204.

46. Zhang Z, Chen $\mathrm{K}$, Ni H. Calcium supplementation improves clinical outcome in intensive care unit patients:a propensity score matched analysis of a large clinical database MIMIC-II. Springerplus. 2015;4:594. 
47. Walsh J, Gittoes N, Selby P. Society for Endocrinology Endocrine Emergency Guidance:Emergency management of acute hypocalcemia in adult patients. Endocr Connect. 2016;5(5):G9-G11.

48. Holick MF, Binkley NC, Bischoff-Ferrari HA, et al. Evaluation,treatmen and prevention of vitamin D deficiency: an Endocrine Society clinical practice guideline. J Clin Endocrinol Metab. 2011;96(7):1911-1930.

49. NICE Guidance. Vitamin D supplement use in specific population groups. Public health guideline (PH 56). 2017.

50. Matysiak-Lusnia K. Vitamin D in critically ill patients. Anaesthesiology Intensive Therapy. 2016;48(3):201-207.

51. Amrein K, Sourij H, Wagner G, et al. Short-term effect of high dose oral vitamin D3 in critically ill vitamin D deficiënt patients:a randomized,double blind,placebo-controlled pilot study. Crit Care. 2011;15(2):R104.

52. Mannstadt M, Clarke BL, Volkes T, et al. Efficacy and safety of recombinant parathyroid hormone (1-84) in hypoparathyroidism ( REPLACE): a double blind placebo-controlled randomised phase 3 study. Lancet Diabetes Endocrinol. 2013;1(4):275-283.
53. Tamara J Vokes, John P Belizikan, Henry G Bone III, et al. Recombinant Human Parathyroid Hormone (rh.PTH(1-84); Parathyroid Hormone rDNA) Improves Hypercalciuria in Patients with Hypoparathyroidism:3 Year Analysis from RACE Study. Endocrine Society. 2017;OR06-OR22.

54. Wang YK, Qin SQ, Ma T, et al. Effects of teriparatide versus alendronate for the treatment of postmenopausal osteoporosis:A meta-analysis of randomized controlled trials. Medicine (Baltimore). 2017;96(21):e6970.

55. Osagle-Clourd L, Sanghani A, Coathup M, et al. Parathyroid hormone 1-34 and skeletal anabolic action. Bone Joint Res. 2017;6(1):14-21.

56. Arika Onisha, Arkia Sato, Masahiro Iwasaku, et al. Human parathyroid hormone for preventing and treating glucocorticoid-induced osteoporosis. Cochrane Musculoskeletal Group. 2014.

57. Lippi G, Fontana B, Avanzini P, et al. Influence of spurious hemolysis in blood gas analysis. Clin Chem Lab Med. 2013;5:1651-1654. 